\title{
Short-term storage of the egg parasitoids, Trichogramma and Trichogrammatoidea
}

\author{
Enakshi Ghosh *iD and Chandish R. Ballal
}

\begin{abstract}
Developing efficient storage technique to produce quality parasitoids is essential for successful bio-control programs. In this study, one cold storage temperature for eight species/strains of Trichogramma and Trichogrammatoidea was tested. Pupae of Trichogramma japonicum Ashmead, T. achaeae Nagaraja and Nagarkatti, T. embryophagum Hartig, T. cordubensis Vargas and Carbello, Trichogrammatoidea bactrae Nagaraja, and three strains of T. chilonis (lab, Nilgiris, and Kodaikanal) were stored at $10{ }^{\circ} \mathrm{C}$ (with L:D -8:16 and RH 70\%) for different durations (0, 10, 20, 30, 40, 50, and 60 days). The effect of storage duration on biological parameters of the parasitoids was checked by recording their percent of adults' emergence and longevity. Obtained data showed species-/strain-specific variations in their storage amenability. T. chilonis strain recorded the highest cold storage capability followed by T. chilonis Kodaikanal and T. cordubensis with $62-68 \%$ after 50 days of storage. Considering a minimum of $60 \%$ emergence rate and 3 days of longevity, 1 month of storage duration can be recommended for T. chilonis lab, T. japonicum, and T. achaeae at $10{ }^{\circ} \mathrm{C}$. Trichogrammatoidea bactrae was unsuitable for storage at this temperature as it failed to emerge even after the minimum storage duration.
\end{abstract}

Keywords: Cold-storage, Trichogramma, Trichogrammatoidea, Emergence rate, Longevity

\section{Background}

Use of chemical pesticides is popular due to its rapid control action. However, unrestricted use of pesticides is the main reason for causing enormous damage to the environment and consumer's health (Gupta and Dikshit 2010). An eco-friendly alternative is using natural enemies like the egg parasitoids, Trichogramma spp. The genera Trichogramma and Trichogrammatoidea have gained an attention as they are capable of reducing pest damage in corn, cole, rice, sugarcane, vegetables, fruit trees, and stored grains (Li 1994; Smith 1996; Gagnon et al. 2017). Due to their worldwide success, these minute polyphagous endo-parasitoids are being commercially produced. Therefore, the commercial insectaries are challenged with a synchronous production rate during the seasonal high market demands. To address this problem, developing a suitable user-friendly storage protocol becomes mandatory.

In India, 28 different species of Trichogramma and Trichogrammatoidea have been recorded. Among them, T. chilonis (Ishii) and T. japonicum (Ashmead) are the

\footnotetext{
* Correspondence: enakshi.ghosh1@gmail.com

ICAR-National Bureau of Agricultural Insect Resources, P. Bag No. 2491, H.A Farm post, Bellary Road, Bangalore-24, India
}

highly successful ones for pest management in tomato, sugarcane, cotton, and rice ecosystems, while $T$. achaeae Nagaraja and Nagarkatti has showed promising results against Achaeae janata (Linn.) (Noctuidae) on castor. Trichogramma cordubensis Vargas and Carbellois is an exotic species, which is used world-wide to control Autographa gamma (L.), Chrysodeixis chalcites (Esper), Phlogophora meticulosa (L.), Peridroma saucia (Hübner), Xestia c-nigrum (L.), and Noctua pronuba (L.) (Garcia et al. 1995; Lingappa and Hegde 2001; Singh et al. 2001; Lalitha and Ballal 2015). Trichogrammatoidea bactrae Nagaraja was tested against rice leaf folder, Cnaphalocrocis medinalis, and emerged out to be a highly promising bioagent (Perera et al. 2015). In India, T. chilonis is considered as the most promising indigenous species which has a wider host range and high survival capacity. Hence, in the present study, three strains of $T$. chilonis (viz. Nilgiris, Kodaikal, and lab) along with five other potential species (T. cordubensis, T. japonicum, T. achaeae, T. embryophagum Hartig, Tr. bactrae) were chosen to develop a suitable storage protocol for their continuous mass production and also to cater to their appropriate delivery by minimizing their hatching rate in transit. 


\section{Materials and methods}

Maintenance of Trichogramma and Trichogrammatoidae spp.

Pure cultures of $T$. japonicum (National Accession No: NBAII-MP-Tr-65), T. achaeae (NBAII-MP-Tr-06), T. cordubensis (NBAII-MP-Tr-55), T. embryophagum (NBAIIMP-Tr-02), Tr. bactrae (NBAII-MP-Tr-58), and three strains of $T$. chilonis viz. two high altitude strains, collected from Nilgiris (NBAII-MP-Tr-23a), Kodaikanal (NBAIIMP-Tr-23b), and lab strain (NBAII-MP-Tr-13), were maintained in the insectary of ICAR-NBAIR, Bangalore, India. An alternate laboratory host Corcyra cephalonica Stainton (Lepidoptera: Pyralidae) was used for rearing the culture following the protocol suggested by Lalitha and Ballal (2015). To create an experimental stocks, UV-irradiated (30 W UV tube for $45 \mathrm{~min}$ at a distance of $2 \mathrm{ft}$ ) C. cephalonica eggs were glued on thick paper cards $(15 \times 10 \mathrm{~cm})$. These eggs are exposed to females in the ratio of 40:1 until adult mortality. Culture of each species/strain was maintained in tubes at $25 \pm 1{ }^{\circ} \mathrm{C}$, with 14 -h light and $65 \pm 10 \%$ $\mathrm{RH}$ to be used in the experiments.

\section{Pupal stage storage of Trichogramma and Trichogrammatoideae at $10^{\circ} \mathrm{C}$}

Freshly collected Corcyra eggs ( 0 to 4 h old) were UV irradiated. Hundred eggs were pasted on a thick paper card $(2 \times 1 \mathrm{~cm})$ and exposed to freshly emerged adults (females: host eggs- 1:30) for $24 \mathrm{~h}$ to get parasitized cards ('Tricho cards'). These cards were incubated at $26{ }^{\circ} \mathrm{C}$ (with L:D $12: 12$ and $\mathrm{RH} 70 \pm 10 \%)$ until the turning of the host egg color to black (indicating the formation of the wasp pupae, approximately 4-5 days). The parasitized cards were placed in a BOD (biological oxygen demand) set at $10{ }^{\circ} \mathrm{C}$ with L:D 8:16 and RH $70 \pm 10 \%$ for different treatment durations $(10,15,20,25,30,35,40,50$, and 60 days $)$. These cards were periodically removed and incubated at $26{ }^{\circ} \mathrm{C}$ for parasitoids' emergence. The emerged adults were provided with $10 \%$ honey solution as diet. The un-stored batches kept at $26^{\circ} \mathrm{C}$ (with L:D 12:12 and RH $70 \pm 10 \%$ ) were considered as a control. Each treatment had five replications ( 1 card $=100$ eggs, 5 replications $=5$ cards $/ 500$ eggs $)$.

\section{Statistical analysis}

Data were analyzed, using one- and two-way analysis of variance (ANOVA) (SPSS 16.0) to evaluate the effect of main treatments (i.e., species/strains of Trichogramma and durations of storage) on parasitoid performance. When statistical difference existed between data sets, Fisher's LSD test was performed to separate the means. The mean percentage values $(X \pm 0.5)$ were subjected to angular transformation and whole numbers to square root transformation $(\sqrt{X+0.5})$ when large variations were observed among the data sets.

\section{Results and discussion}

In general, storage of Trichogramma pupae, at $10{ }^{\circ} \mathrm{C}$, reduced their emergence and longevity, regardless of their storage durations. For $T$. chilonis Kodaikanal and $T$. japonicum, the emergence rates after 20 days of storage were comparable to the respective control ( $F-19.3$; df- 8, 36; $P \leq 0.0001, F-18.4$; df- 5, 24; $P \leq 0.0001$, respectively). Trichogramma embryophagum and $T$. chilonis Nilgiris recorded equal emergence rate after 30 and 25 days of storage durations $(F-14.4$; df- 8,$36 ; P \leq 0.0001, F-86$; df9,$40 ; P \leq 0.0001$, respectively). Storage of $T$. cordubensis resulted in significant reduction in emergence and longevity rates to that observed for control $(F-31$; df- 7,32 ; $P \leq 0.0001)$.

Trichogramma chilonis Nilgiris emerged out to be the most amenable species/strain for storage (60 days) followed by $T$. chilonis Kodaikanal and T. embryophagum (50 days), and with respect to their emergence rates (Fig. 1). However, longevity, recorded after 10 days of storage in case of $T$. achaeae, T. embryophagum, and $T$. chilonis lab, showed insignificant differences than their respective controls $(F-48.8$; df- 5,$24 ; P \leq 0.0001, F-58$; df- 8, 36; $P \leq 0.0001, F-39$; df- 5, 24; $P \leq 0.0001)$. Statistically, $T$. cordubensis could retain its longevity the best after storage followed by T. embryophagum and T. chilonis Nilgiris (Fig. 2).

Considering a minimum 60\% emergence rate and 3 days of longevity, the optimum duration for storing of T. chilonis lab, $T$. japonicum, and $T$. achaeae was 30 days (F-9.3; df- 5, 24; $P \leq 0.0001, F-18.4$; df- 5, 24; $P \leq 0.0001$, $F-10.5$; df- 5,$24 ; P \leq 0.0001)$, while $T$. cordubensis recorded 40 days of storage suitability $(F-31.2$; df- 7,32 ; $P \leq 0.0001)$. Tr. bactrae failed to emerge even after the shortest duration of storage of 10 days.

Quiescence is an adaptation to resist unforeseen environmental changes, and it is a popular approach to use this naturally occurring phenomenon to improve storage of Trichogramma. During this phase of quiescence, the cells undergo a hypo-metabolic state and the capacity to retain this state is essentially species/strain specific (Vargas et al. 2014). Environmental factors like temperature and photoperiod are known to be the deciding factors for this adjustment. Previous study on threshold temperature analysis pointed out their lower threshold temperature (LT) to range between 9 and $12{ }^{\circ} \mathrm{C}$, and this indicated that their normal development might get affected below this range (Haile et al. 2002; Rundle and Hoffmann 2003; Foerster and Foerster 2009; Ghosh et al. 2017). The most common obstacle of Trichogramma storage is its performance contraction upon storage. Hence, choosing $10{ }^{\circ} \mathrm{C}$ was logical in order to preserve their biological attributes without much alterations.

As quiescence is an adaptation against cold environment, better adaptation is expected from species/strains 


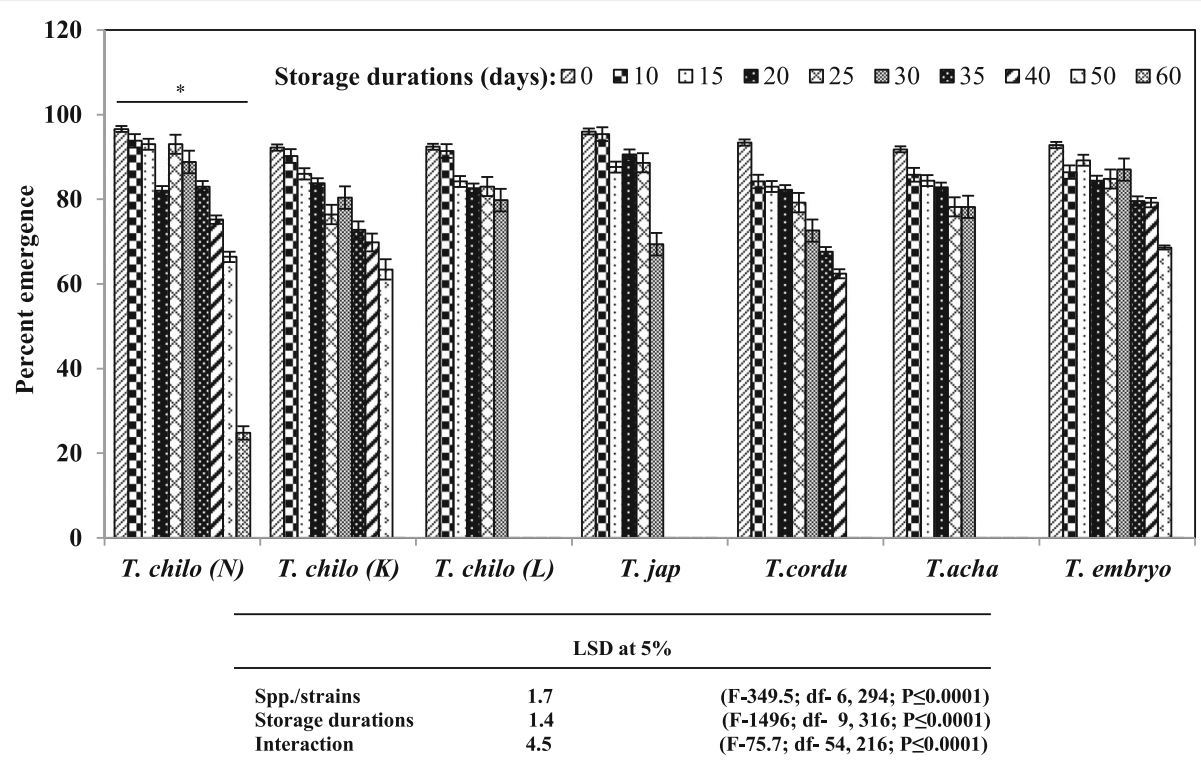

Fig. 1 Emergence of different spp./strains of Trichogramma after their pupal stage storage on Corcyra cephalonica eggs at $10{ }^{\circ} \mathrm{C}(\mathrm{L}: \mathrm{D}$ 8:16, RH 70 $\pm 10 \%)$. Control treatment (0 days): un-stored batch of Trichogramma pupae. T. chilo (N), Trichogramma chilonis Nilgiris; T. chilo (K), T. chilonis Kodaikanal; T. chilo (L), T. chilonis Lab; T. jap, T. japonicum; T. cordu, T. cordubensis; T. acha, T. achaeae; T. embryo, T. embryophagum

from cooler geographical origin. In this study, the exotic species T. embryophagum and T. cordubensis were imported from France. In spite of their origin, they failed to supersede in their performance against the indigenous strains of $T$. chilonis (except lab strain). The Nilgiris strain of T. chilonis could emerge even after 60 days of storage which showed that this strain was the coldest adapted strain among all. However, considering the percent emergence rate of minimum $60 \%$, both strains of $T$. chilonis (viz. Nilgiris and Kodaikanal) and T. embryophagum were amenable for 50 days of storage. T. cordubensis showed significantly less amenability of 40 days, but it was the best in terms of longevity followed by T. chilonis Nilgiris strain. Previous study by Jalali and Singh (1992) staggered the

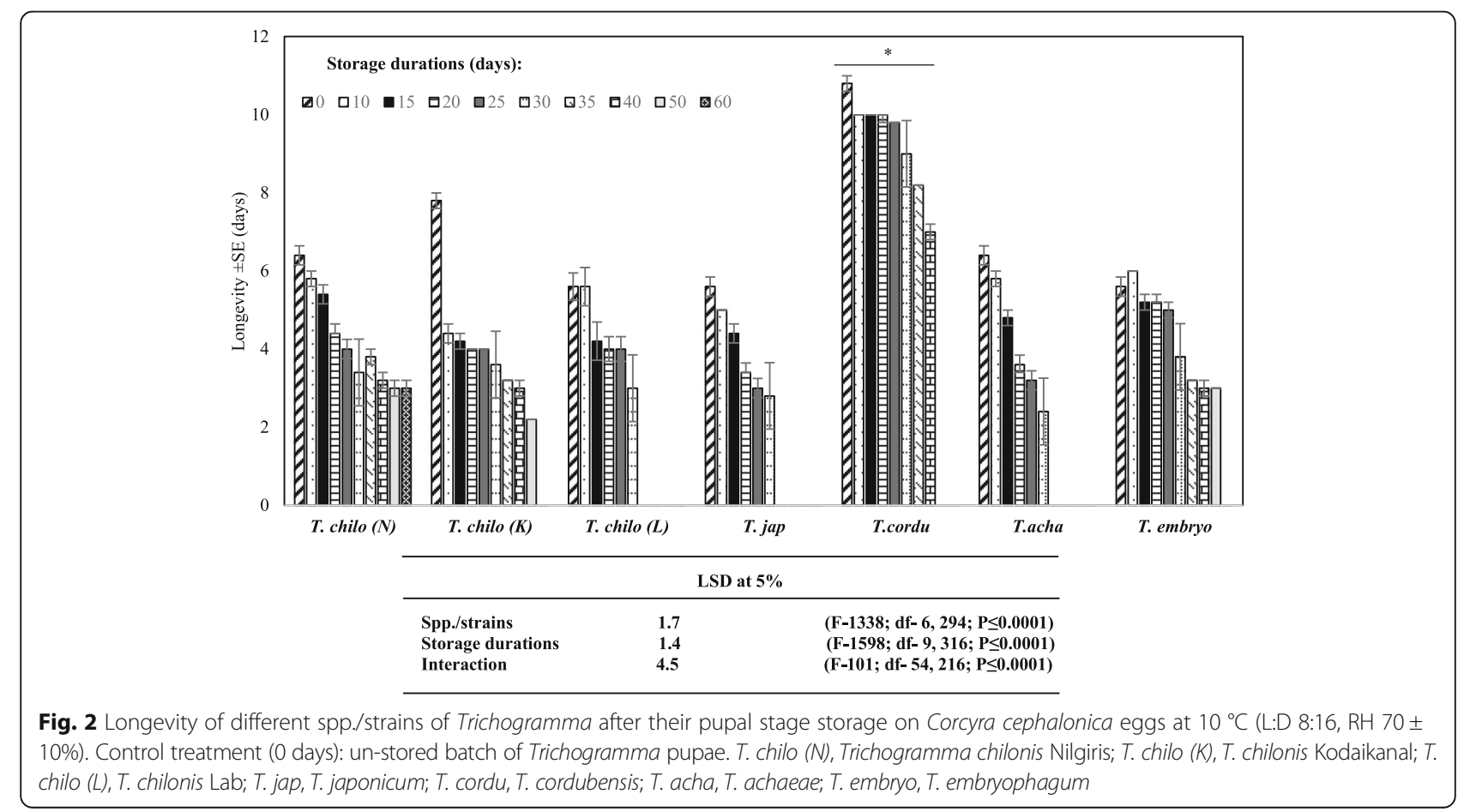


development of $T$. chilonis for up to 14 days with $60 \%$ emergence rate, but our findings prolonged the storage without reducing its emergence rate for up to 50 days. Vieira and Tavares (1992) could store T. cordubensis on Ephistia kuehniella Zeller eggs for 135 days at $0.7{ }^{\circ} \mathrm{C}$. Reduced storage duration could primarily be due to differences in host eggs as the host physiology contributes greatly towards their cold tolerance (Laing and Corrigan 1995). The other reasons for inferior performance might be due to continuous lab rearing which caused bio-deterioration in Trichogramma (Ghosh and Ballal 2017). Due to the differences observed between freshly field collected Nilgiris, Kodaikanal strain, and lab strain of T. chilonis. Other tested species like $T$. achaeae showed 30 days of storage capacity which is comparable to the previous report by Jalali and Singh (1992). On the other hand, Tr. bactrae aborted their emergence upon storage, indicating the lack of cold adaptation capability. However, storing Tr. bactrae on different host eggs might improve the storage amenability of this species.

\section{Conclusions}

Data generated on the emergence rate and longevity upon storage at $10{ }^{\circ} \mathrm{C}$ led to conclude that one single temperature could be capable of facilitating the storage of seven different species/strains of Trichogramma. Storing at this temperature can provide a minimum of $70 \%$ emergence rate and 3 days of longevity after 30 days of storage irrespective to the species/strains tested.

\section{Acknowledgements}

The funding provided by the Department of Biotechnology, Government of India, for this research project (code: BT/PR3339/AGR/5/558/2011) is gratefully acknowledged. The authors thank Dr. Y. Lalitha for the cultures of C. cephalonica and T. chilonis $15^{\circ} \mathrm{C}$ strains.

\section{Funding}

Current work was funded by the Department of Biotechnology, Government of India (research project code: BT/PR3339/AGR/5/558/2011).

\section{Availability of data and materials}

Not applicable. Unwilling to submit the raw data's as they are being used for developing suitable techniques for commercialization.

\section{Authors' contributions}

EG participated in the design of the study, conducted the experiments, prepared the manuscript, and performed the statistical analysis. CRB contributed to the design of the study and preparation of the manuscript. Both authors read and approved the final manuscript for publication.

Ethics approval and consent to participate

Not applicable.

\section{Consent for publication}

Not applicable.

\section{Publisher's Note}

Springer Nature remains neutral with regard to jurisdictional claims in published maps and institutional affiliations.

Received: 1 December 2017 Accepted: 27 February 2018

Published online: 05 April 2018

\section{Reference}

Foerster RM, Foerster AL (2009) Effect of temperature on the immature development and emergence of five species of Trichogramma. BioControl 54: 445-450

Gagnon EA, Audette C, Dural B, Boisclair J (2017) Can the use of Trichogramma ostriniae (Hymenoptera: Trichogrammatidae) to Ostrinia nubilatis (Lepidoptera: Crambidae) be economically sustainable for processing sweet corn? J Econ Entomol 110:59-66

Garcia P, Oliveira L, Tavares J (1995) Comparative biology of three Trichogramma spp. populations captured in Azores. Bol Mus Munic Funchal 4(suppl):311-318

Ghosh E, Ballal CR (2017) Diapause induction and termination in Indian strains of Trichogramma chilonis (Hymenoptera: Trichogrammatidae). Can Entomol 149(5):605-615

Ghosh E, Ballal CR, Verghese A (2017) Temperature based differences in biological parameters of some potential species/strains of Trichogramma. J Biol Control 31(2):82-89

Gupta S, Dikshit AK (2010) An ecofriendly approach for pest control. J Bio Pest 3(1):186-188

Haile AT, Hassan SA, Ogol CKPO, Baumgärtner J, Sithanantham S, Monje JC, Zebits CPW (2002) Temperature-dependent development of four egg parasitoids Trichogramma species (Hymenoptera; Trichogrammatidae). Biocontrol Sci Tech 12:555-567

Jalali SK, Singh SP (1992) Differential response of four Trichogramma species to low temperatures for short term storage. Entomophaga 37:159-165

Laing JE, Corrigan JE (1995) Diapause induction and post-diapause emergence in Trichogramma minutum Riley (Hymenoptera: Trichogrammatidae): the role of host species, temperature and photoperiod. Can Entomol 127:103-110

Lalitha Y, Ballal CR (2015) Influence of seasons and inoculum dosages on the production efficiency of Corcyra cephalonica Stainton. Biol Control 29(1):25-30

Li LY (1994) Worldwide use of Trichogramma for biological control of different crops: a survey. In: Wajnberg E, Hassan SA (eds) Biological control with egg parasitoids. CAB International, Wallingford, pp 37-53

Lingappa S, Hegde S (2001) Exploitation of bio-control potential in the management of insect pests of pulse crops. In: Biocontrol potential and its exploitation in sustainable agriculture, vol 2, pp 321-344

Perera MCD, Hemachandra KS, Sirisena UGAI (2015) Trichogrammatoidea bactrae (Hymenoptera: Trichogrammatidae): a potential biocontrol agent of rice leaf folder. Trop Agric Res 26(3):537-546

Rundle BJ, Hoffmann AA (2003) Overwintering of Trichogramma funiculatum carver (Hymenoptera: Trichogrammatidae) under semi-natural conditions. Environ Entomol 32:290-298

Singh SP, Murphy ST, Ballal CR (2001) Augmentative biocontrol in India. In: Singh et al (eds) Proceedings of the ICAR-CABI workshop, pp 1-20

Smith MS (1996) Biological control with Trichogramma: advances, successes, and potential of their use. Annu Rev Entomol 41:375-406

Vargas HCM, Farnesi LC, Martins AJ, Valle D, Rezende GL (2014) Serosal cuticle formation and distinct degrees of desiccation resistance in embryos of the mosquito vectors Aedes aegypti, Anopheles aquasalis and Culex quinquefasciatus. J Insect Physiol 62:54-60

Vieira V, Tavares J (1992) Produção em massa de Ephestia kuehniella Zeller (Lep., Pyralidae) IV-Técnicas de recolha dos adultos e ovos Açoreana, vol 7, pp 461-470 